IRA-International Journal of Education \& Multidisciplinary Studies

ISSN 2455-2526; Vol.04, Issue 01 (2016)

Institute of Research Advances

http://research-advances.org/index.php/IJEMS

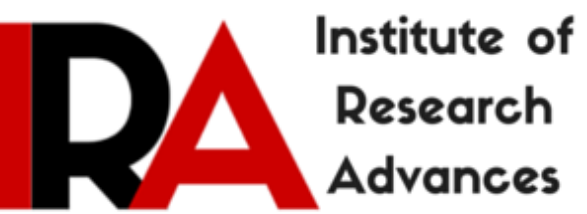

\title{
Verification and Validation as a Key Driver in Modern Engineering Education
}

\author{
Sophie Hong Rui Lo \\ School of Engineering \\ Manchester Metropolitan University \\ Chester Street, Manchester M1 5GD \\ United Kingdom
}

DOI: http://dx.doi.org/10.21013/jems.v4.n1.p18

\section{How to cite this paper:}

Lo, S. H. R. (2016). Verification and Validation as a Key Driver in Modern Engineering Education. IRA International Journal of Education and Multidisciplinary Studies (ISSN 2455-2526), 4(1). doi:http://dx.doi.org/10.21013/jems.v4.n1.p18

(C) Institute of Research Advances

\section{(cc) EY-NC}

This works is licensed under a Creative Commons Attribution-Non Commercial 4.0 International License subject to proper citation to the publication source of the work.

Disclaimer: The scholarly papers as reviewed and published by the Institute of Research Advances (IRA) are the views and opinions of their respective authors and are not the views or opinions of the IRA. The IRA disclaims of any harm or loss caused due to the published content to any party. 


\begin{abstract}
In the era of fast technological development in all engineering disciplines, how to improve the employability of engineering graduates imposes an even greater challenge than ever before to the educators in higher education. What constitutes key knowledge and skills for future professional engineers and how they can be developed in the graduates through our engineering courses are important questions whose answers can have a profound impact on the success of the engineering education.

In this paper, the strategy of using verification \& validation $(V \& V)$ as a key driver for quality learning in engineering education is proposed. The rationale of the proposed strategy and the requirements for its success are explained. An example of implementing this strategy is illustrated. In the conclusion section, a current and common issue is raised.
\end{abstract}

Keywords: Verification \& validation, simulation-driven product development, integrated teaching, employability

\title{
Introduction
}

In the era of fast technological development in all engineering disciplines, how to improve the employability of engineering graduates imposes an even greater challenge than ever before to the educators in higher education. What constitutes key knowledge and skills for future professional engineers and how they can be developed in the graduates through our engineering courses are the main focus of this paper.

Simulation driven product development (SDPD) has brought about a paradigm shift in many manufacturing companies in recent years and will be the dominant form of new product development in the forthcoming global industrial revolution that is characterized by smart manufacturing and mass customization. A key feature of SDPD is the integration of design, analysis, computer simulation and physical testing organized and conducted in a co-ordinated dynamic process with the aim of developing a fully functional and highly optimized virtual prototype before the first physical prototype is produced (Pavasson, J., et al, 2014). Since such virtually developed products must be commercially credible, a critical element of the SDPD process is the verification and validation $(\mathrm{V} \& \mathrm{~V})$ of the digital model and this is often achieved through a series of developmental analysis and physical testing at different stages of the virtual product development process. 'There is clear evidence that digital domain design verification and validation is a high industrial priority and there is evident research focus in such methods, as well as considerable coverage via international standards.' (Maropoulos, P. G. \& Ceglarek, D., 2010). Engineering education should aim to equip the graduates with the mentality and the competence for them to take responsible roles in such processes.

With the industry requirements as a reference, a new strategy of engineering education is being proposed, i.e., using $\mathrm{V} \& \mathrm{~V}$ of computer simulation models to organize the teaching and learning activities, to drive the students' motivation for learning and investigation, and to develop professional engineer's mentality and attitude in students.

Engineering science teaching, $\mathrm{CAD} / \mathrm{CAE}$ skills training and laboratory experiments already existed on our courses and indeed most of the engineering courses in higher education institutions but they are often treated as separately taught and assessed elements. By adopting the proposed strategy, these activities are integrated together in the V\&V process. Such integration generates multiple and significant benefits over the traditional approach including enhanced quality and 
standard of the student learning outcomes, improved effectiveness and efficiency of the teaching $\&$ learning process and increased level of employability. The proposed strategy and benefits will be further explained in the following sections with an example.

\section{Overview of the proposed strategy}

Although apparently there are different statements defining verification \& validation in different disciplines (Boehm, B. W.,1984; Oberkampf, W.L., 2012; ISO 9001:2008, 2008)., a generic definition states that

- Verification: Are we building the system right?

- Validation: Are we building the right system?

In the context of the proposed strategy of using $\mathrm{V} \& \mathrm{~V}$ as a key driver for quality learning in engineering education, the $\mathrm{V} \& \mathrm{~V}$ process can be described as follows.

The engineering system chosen for the study is subject to theoretical analysis, computer simulation/virtual prototyping and physical testing. The T\&L program aims to produce a digital model that can re-produce the behavior of the physical system under the prescribed operating conditions. Verification will be carried out first by comparing the theoretical solution (or any independent analytical solution) with the results from the digital model simulation under any suitable excitation to confirm 'building the system right'. Then validation will be carried out by comparing the physical testing results with the digital model simulation results subject to the same operating condition to confirm 'building the right system'.

To make the V\&V be carried out successfully by a large number of undergraduate students studying a unit, there are some requirements worth mentioning as they may have an impact on the initial cost for such T\&L programs.

(1) The quality of the physical system and its measurement system must be good in the sense that uncertainties in modelling and in results should be minimal or at least well understood by the tutors. Otherwise the already challenging tasks involved in the V\&V process will be made more complex and that can be demoralizing for students.

(2) The physical system should be suitable for being mathematically modelled or virtually prototyped by students. The students should be able to access all modelling information of the system.

(3) The supervisory academic team needs to be competent in the V\&V process themselves since unlike those self-contained individual elements, such processes consist of multiple sub-processes and they interact with each other so it is more difficult to find relevant technical support from the standard learning resources.

However the benefits that the proposed strategy can achieve over the traditional approach are multiple and significant, chiefly,

(a) There is a huge demand by a wide range of industry for graduates with the knowledge, skills and experience of $\mathrm{V} \& \mathrm{~V}$ so the graduate job prospect is improved.

(b) The T\&L program with this strategy not only teaches the technical contents of those individual elements, but also their integrated use in the V\&V process. This additional knowledge and experience can enhance students' understanding significantly. 
(c) The $V \& V$ process puts the learner in the driving seat, especially when the student starts to examine causes of discrepancy. This self-motivation is the most important factor for achieving a successful learning outcome.

(d) The V\&V process automatically makes the students examine all aspects critically when trying to uncover the reasons for discrepancies and this experience is highly valuable to developing intellectual power and gaining deep understanding in the learner.

(e) The $\mathrm{V} \& \mathrm{~V}$ process is fundamentally an iterative debugging process and it inevitably causes various frustrations as well as delights to students during the process. With sufficient encouragement and guiding support, this can become an excellent journey for students to cultivate perseverance that will help them achieve success not only on this course but also in their future careers.

To summarize, the $\mathrm{V} \& \mathrm{~V}$ process is a powerful tool for raising the quality and standard of engineering education and developing the attitude and abilities of professional engineers in students.

It is expected that the $\mathrm{T} \& \mathrm{~L}$ programs with imbedded $\mathrm{V} \& \mathrm{~V}$ processes will flourish on campusbased engineering courses as physical experiments are what the virtual courses lack.

\section{An example}

An example in teaching a computer-aided fatigue analysis (CAFA) unit will be presented. Some points mentioned in the previous section will be further explained.

In this example, the engineering system for study is shown in figure 1. This rig consists of a top cantilever beam connected to a vibrating assembly through a spring. The main beam that is pivoted to the frame has an out-of-balance motor attached to it. When the motor runs, the out-ofbalance force causes the whole system to vibrate and the cyclic force in the spring makes the top cantilever beam bend periodically. There is a notch (a small hole) in the top beam so stress concentration occurs around the notch. The shortest fatigue life of the cantilever beam is expected to occur at the hole rim. The measurement system includes an accelerometer on the main beam, a force transducer in the spring load path, and a set of strain gauges on the cantilever beam both adjacent to the hole and remote from the hole.

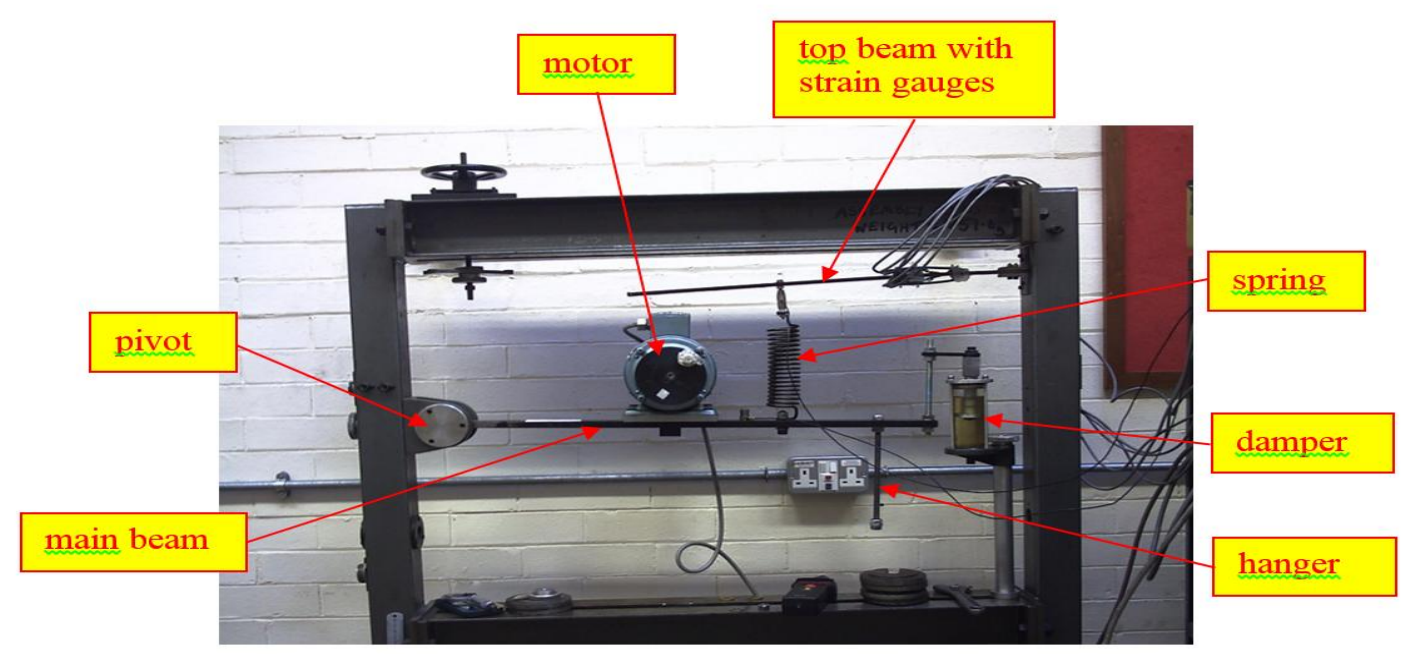

Figure 1 A vibrating fatigue test rig 
The assembly with the main beam, spring and damper was purchased as a standard teaching equipment for studying single-degree-of-freedom vibration. In order to make a rig for studying fatigue in the CAFA unit, it was modified by retro-fitting the top cantilever beam with a notch. This vibrating fatigue rig is excellent for illustrating the CAFA concepts, methods and process and is suitable for students to do coursework. Students can disassemble and assemble the system, take measurements of dimensions of the parts and weigh the masses. They can also determine the spring stiffness and the damping coefficient through testing themselves. So students can determine all modelling information themselves. Furthermore, each component, sub-system as well as the complete system can be analyzed separately using the vibration theories learned on the course and they can also be tested separately. Therefore the $V \& V$ process can be carried out at each level. These are some of the most desirable characteristics that should be taken into account when selecting the engineering system for a $T \& L$ program with imbedded $V \& V$ requirements.

CAFA is one of the most demanding virtual tests in the SDPD process. On the one hand, fatigue crack initiation is a highly localized phenomenon often occurring at some sharp geometric feature and the fatigue life is extremely sensitive to the level as well as the state of the dynamic stress at the critical location. On the other hand, CAFA utilizes a suite of CAE software working together to calculate the accumulated fatigue damage and predict fatigue life. The CAFA process can be described by the flow chart diagram in figure 2 .

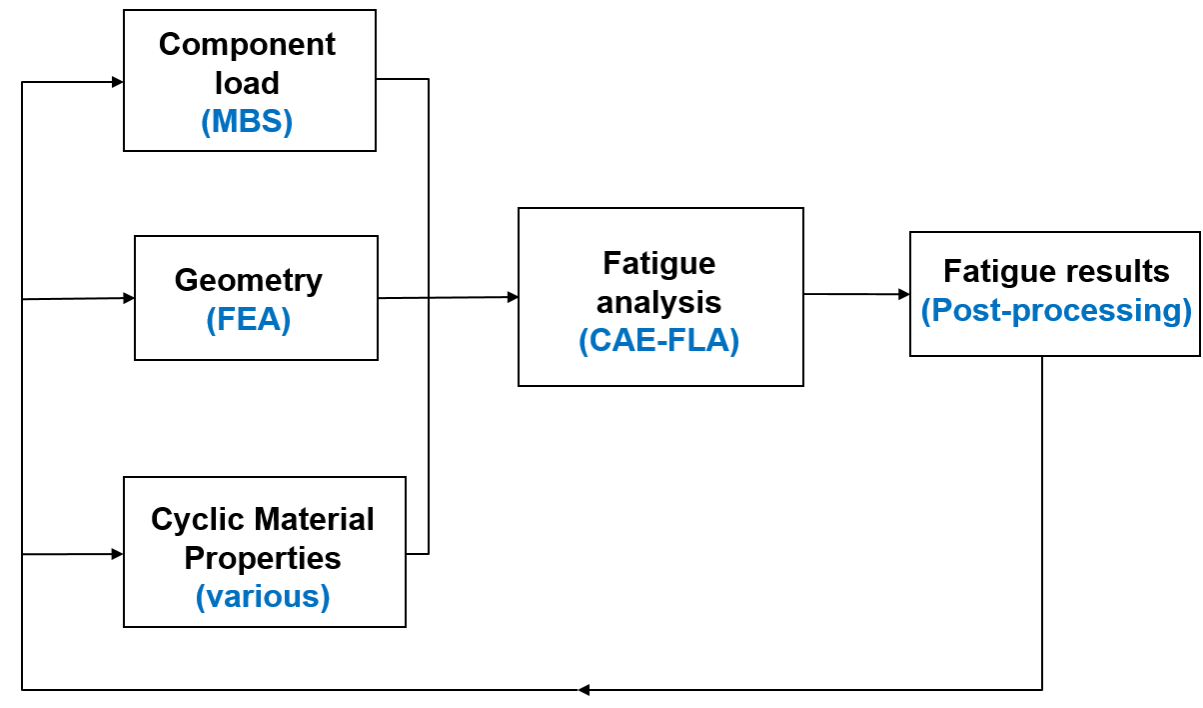

Figure 2 A CAFA flow chart

It can be seen from figure 2 that a fatigue analysis requires three major inputs including (a) load histories on the critical component from multi-body dynamic simulation (MBS), (b) stress distribution including stress concentration effect from finite element analysis (FEA) and (c) cyclic material properties. Each of these inputs has its particular challenges in the context of fatigue analysis and any error contained in the information passed on to CAE-based fatigue life analysis(CAE-FLA) will affect the fatigue analysis results. Therefore, in principle, each of these inputs should be subject to the $\mathrm{V} \& \mathrm{~V}$ process to minimize its carry-forward error. MBS applies the system input, e.g., the out-of-balance force in this example, to the virtual model and simulates the component load, i.e., the spring force acting on the top cantilever beam, that will be sent to CAE-FLA. FEA takes the CAD geometry of the component of interest that contains the notch feature, i.e., the top cantilever beam and carries out a stress calculation at each node in the FE 
model. The cyclic material property is often one of the major sources of uncertainty in real life applications and usually fatigue tests of the actual material have to be conducted for safety critical projects. In the CAFA unit, the data from the material database are used which correspond to a $50 \%$ certainty of survival based on the laboratory material testing results. Finally, CAE-FLA takes the three inputs as described above and calculates the fatigue damage distribution using the user selected method.

It is clear that there are numerous potential error sources in the CAFA process. Therefore, to minimize the error in the final fatigue analysis results, it is of critical importance that the quality of the results from every aspect is checked using the V\&V method. This concept was emphasized strongly in the teaching.

Below shows some examples of the $\mathrm{V} \& \mathrm{~V}$ activities and results for the vibrating fatigue system.

For the virtual model of the system shown in figure $3, \mathrm{~V} \& \mathrm{~V}$ was carried out in

- Case(1): at the component level for the top beam only

- Case(2): at the sub-system level for the vibrating assembly only

- Case(3): at the system level for the complete model

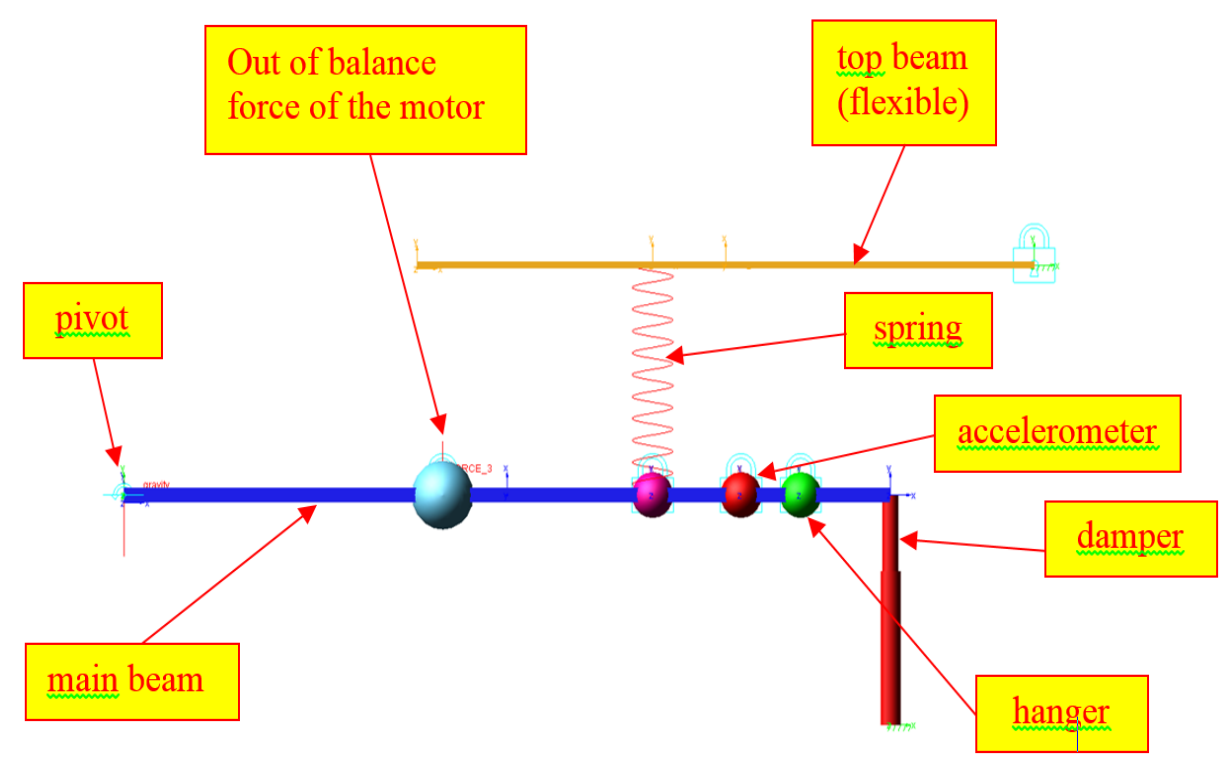

Figure 3 Virtual model of the vibrating fatigue test rig 
The results for these three $\mathrm{V} \& \mathrm{~V}$ cases are summarized in figure 4 .

Case (1): Top beam lateral vibration only
Natural frequency (Hz)
\begin{tabular}{|c|c|c|c|}
\hline MODE & $\begin{array}{c}\text { Euler- } \\
\text { Bernoulli } \\
\text { Theory }\end{array}$ & $\begin{array}{c}\text { Adams } \\
\text { Model }\end{array}$ & $\begin{array}{c}\text { Physical } \\
\text { Test }\end{array}$ \\
\hline 1 & 14.81 & 14.48 & 14.36 \\
\hline 2 & 94.25 & 91.10 & \\
\hline 3 & 259.6 & 255.38 & \\
\hline
\end{tabular}

The difference in the lowest natural frequency between test $(14.36 \mathrm{~Hz})$ and simulation $(14.48 \mathrm{~Hz})$ is $0.8 \%$

\section{Case (2): SDOF vibration with top beam being fixed}

The difference in the natural frequency between test $(4.22 \mathrm{~Hz})$ and $\operatorname{simulation}(4.19 \mathrm{~Hz})$ is $0.7 \%$.

\section{Case (3): Vibration of the complete system}

The difference in the lowest natural frequency between test $(3.42 \mathrm{~Hz})$ and $\operatorname{simulation}(3.22 \mathrm{~Hz})$ is $5.8 \%$.

Figure 4 Examples of V\&V results

To illustrate some details for Case (3), Figure 5 shows the complete model being simulated, figure 6 shows the list of the modal results calculated from the virtual model, and figure 7 shows the frequency response from the physical testing.

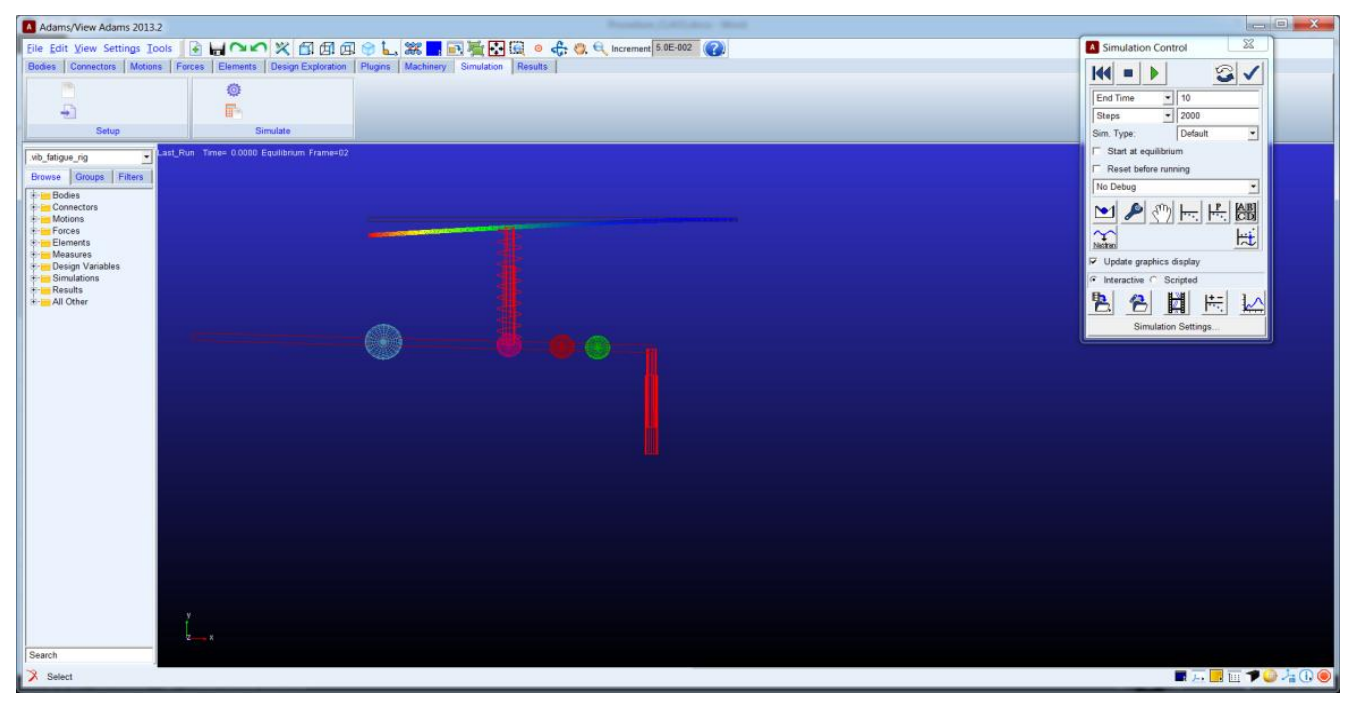

Figure 5 The virtual model being simulated 


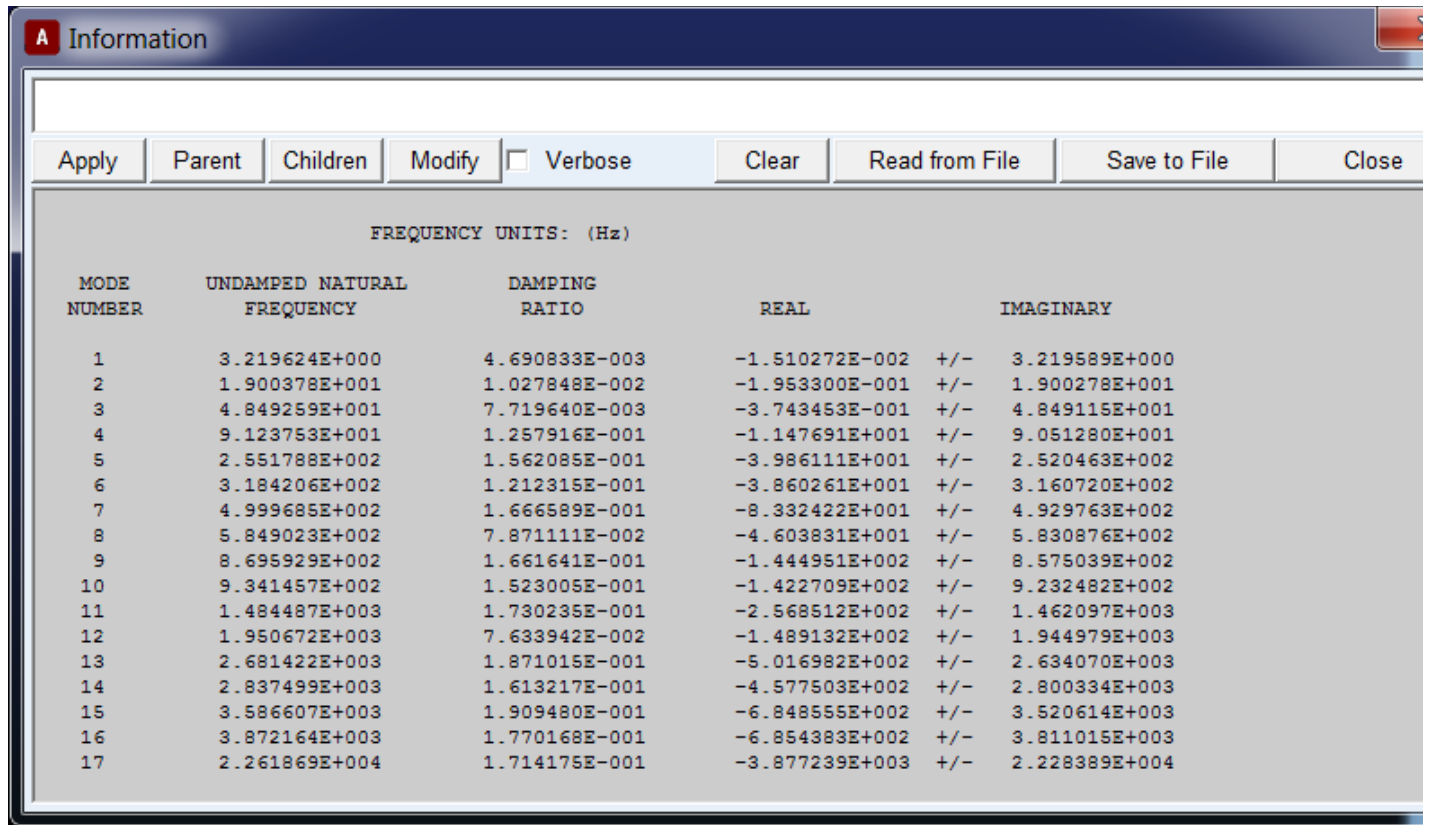

Figure 6 Modal analysis results of the virtual model

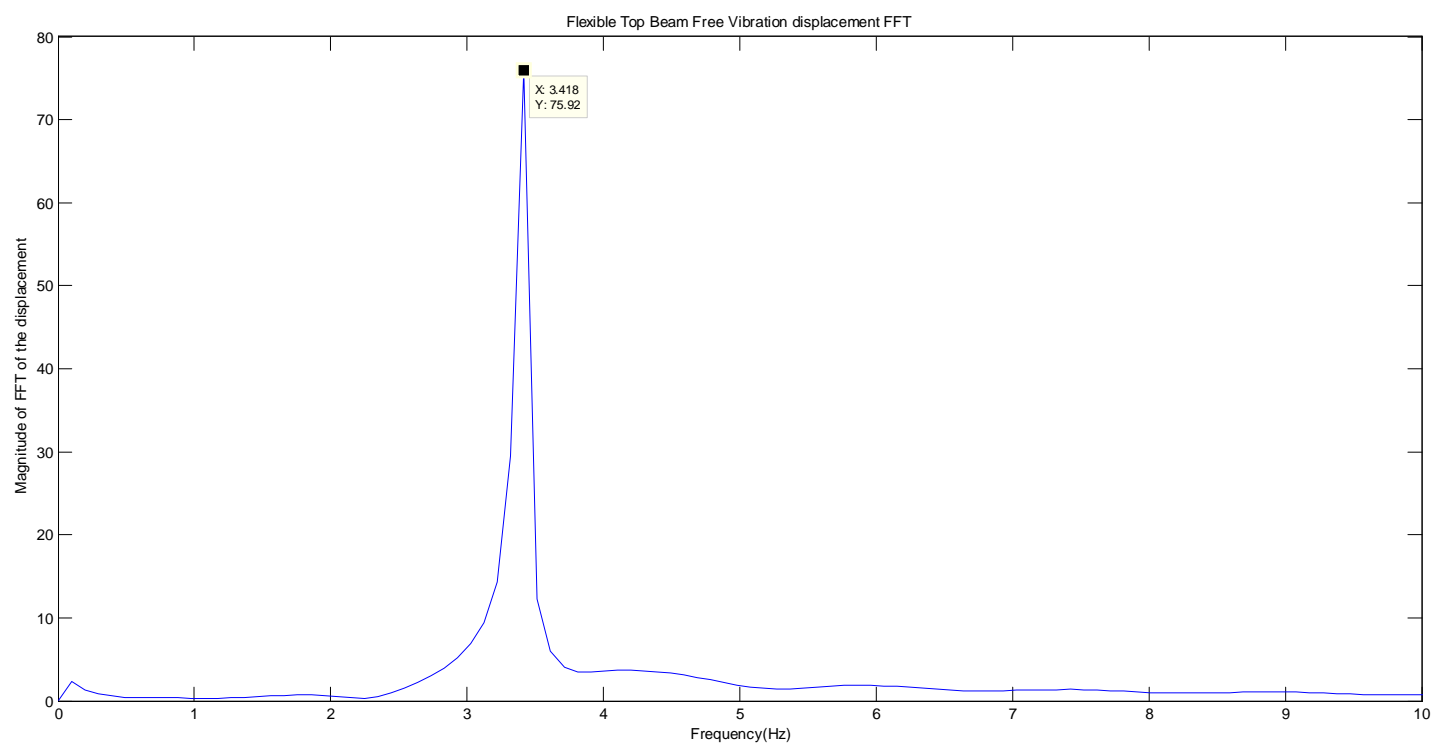

Figure 7 Frequency response from physical testing

The peak frequency $(3.42 \mathrm{~Hz})$ in figure 7 is compared with the $1^{\text {st }}$ natural frequency $(3.22 \mathrm{~Hz})$ on the list in figure 6 as shown in the V\&V Case (3) in figure 4.

\section{Conclusion}

Considering the characteristics of the modern industry and society and the important role of the SDPD approach, it can be stated that there is an increasingly large demand on graduates who are capable of engaging and contributing to the SDPD process in their professional careers. Since the credibility of the digital model for commercial product development is a key requirement for the 
success of the SDPD approach, gaining an understanding of the relevant knowledge and the tools that are used by industry should become an important part of engineering courses.

$\mathrm{V} \& \mathrm{~V}$ as defined in this paper provides a suitable framework to achieve this objective. In addition, $\mathrm{V} \& \mathrm{~V}$ has many other benefits from the educational and pedagogical viewpoints as explained in this paper. With this rationale, the strategy of using $\mathrm{V} \& \mathrm{~V}$ as a key driver for quality learning in engineering education has been proposed.

Implementing the $\mathrm{V} \& \mathrm{~V}$ process in teaching, learning and assessment programs is not a trivial task. As this paper has explained, the quality of the test rig including the measurement system for generating high quality test data and the ability of the teaching staff for guiding and supporting students in a wide range of related academic activities are two most important factors for success.

In addition, for a complete $\mathrm{V} \& \mathrm{~V}$ process, a highly desirable condition is that the test rig be fully accessible by students in terms of obtaining system parameters as well as testing the rig at their individual validation stage. The example has illustrated that using the professionally produced test rig for teaching can be an effective way to achieve the quality standard. However, a difficulty that has been encountered by us and many other HE institutions is that the ratio of the number of students to the number of test rig is too large. It is hoped that the manufacturers of the teaching lab equipment and the HE engineering departments can work together to find a solution to this problem that has the potential of generating a significant and sustained multi-win outcome for the students, the educational institutions and the teaching equipment manufacturers.

\section{References}

Boehm, B. W. (1984). Verifying and validating software requirements and design specifications. IEEE Software, 1(1), 75-88.

ISO 9001:2008 (2008) Quality management systems - Requirements.

Maropoulos, P. G. \& Ceglarek, D. (2010). Design verification and validation in product lifecycle. CIRP Annals - Manufacturing Technology Technology, 59(2), 740-759.

Oberkampf, W.L. (2012) Practical and technical challenges in verification and validation. ASME Verification and validation symposium.

Pavasson, J., Ljung, A. -L., Karlberg, M., Larsson, I. A. S., Johansson,S. \& Lundstrom, T. S. (2014). Challenges and opportunities within simulation-driven functional product development and operation. $3^{\text {rd }}$ International conference on Through-life engineering services. Procedia CIRP $22,169-174$. 